\title{
Precision Micron Hole Drilling Using a Frequency Doubled, Diode Pumped Solid State Laser
}

and Herbert W. Friedman

Lawrence Livermore National Laboratory
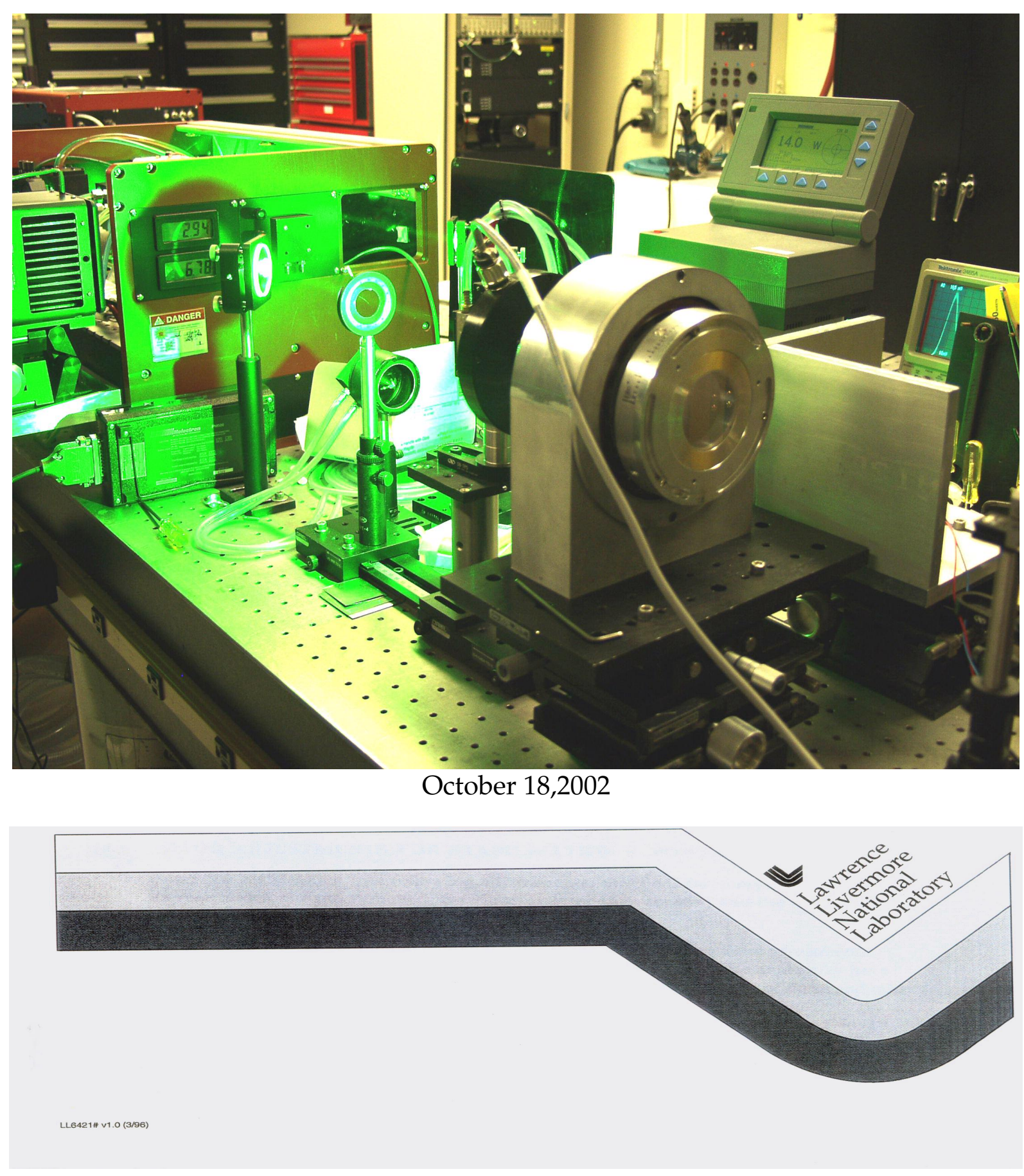
This document was prepared as an account of work sponsored by an agency of the United States Government. Neither the United States Government nor the University of California nor any of their employees, makes any warranty, express or implied, or assumes any legal liability or responsibility for the accuracy, completeness, or usefulness of any information, apparatus, product, or process disclosed, or represents that its use would not infringe privately owned rights. Reference herein to any specific commercial product, process, or service by trade name, trademark, manufacturer, or otherwise, does commercial product, process, or serits endorsement, recommendation, or favoring by the United States not necessarily constitute or imply its endorsement, recommendation, or favoring ox novernment or the University of California. The views and opinions of authors exprester or reflect those of the United States Government or the University of California, and shall not be used for advertising or product endorsement purposes.

This report has been reproduced directly from the best available copy.

Work performed under the auspices of the U.S. Department of Energy by Lawrence Livermore National Laboratory under Contract W-7405-ENG-48. 


\section{DPSSL Laser Hole Drilling}

\section{Background}

This work represents the second phase of a program to demonstrate precision laser drilling with minimal Heat Affected Zone. The technique uses a Diode Pumped Solid State Laser with two wavelengths and two modes of operation. The fundamental mode of the DPSSL at 1.06 microns is used to drill a hole with a diameter of a fraction of a millimeter diameter in a millimeter thick substrate quickly, but with low precision. This hole is then machined to precision dimensions using the second harmonic of the DPSSL Laser at $532 \mathrm{~nm}$ using a trepanning technique. Both lasers operate in the ablative mode with peak powers at or above a giga-watt per square centimeter and pulse durations in the $80-100 \mathrm{~ns}$ range. Under these conditions, the thermal diffusion distance is of the order of a micron or less and that fact coupled with the ablative nature of the process results in little or no HAZ (heat affected zone). With no HAZ, there isn't any change in the crystalline structure surrounding the hole and the strength of the substrate is maintained. Applications for these precision holes include cooling passages in turbine blades, ports for diesel injectors, suction holes for boundary layer control on wings and holes for dies in precision extrusion processes.

\section{Hole Drilling Results}

Demonstration of the first phase using the fundamental mode of the DPSSL Lasers at 1.06 microns was completed on September 28,2001. The second phase began in August 2002 with the DPSSL Lasers configured to produce a high quality beam at the second harmonic, which is $532 \mathrm{~nm}$. A lithium niobate doubling crystal was used inside a simple " $\mathrm{L}$ " configuration cavity with $3 \mathrm{~mm}$ limiting apertures to produce a three times diffraction limited beam. The laser power was $16 \mathrm{~W}$ at $13 \mathrm{kHz}$ and75 $\mathrm{ns}$ (FWHM) duration and when focused to a 10-micron spot diameter produced $26 \mathrm{GW} / \mathrm{cm}^{2}$, well above the threshold for ablation cutting. The laser beam diameter is only $3 \mathrm{~mm}$ so a 4:1 beam expander was used to fill the $10 \mathrm{~mm}$ input of an F1 focusing lens to produce a beam spot diameter of $10 \mu$, as shown in Figs. 1 and 2. 


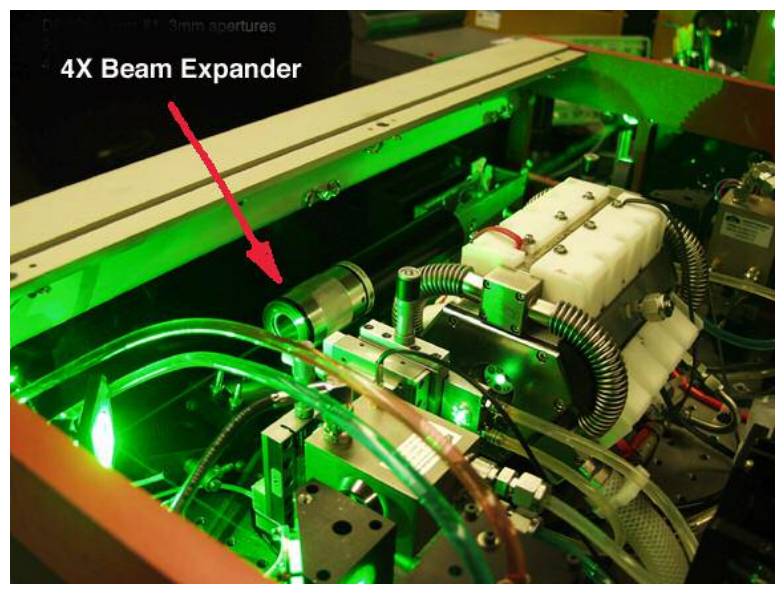

Fig. 1

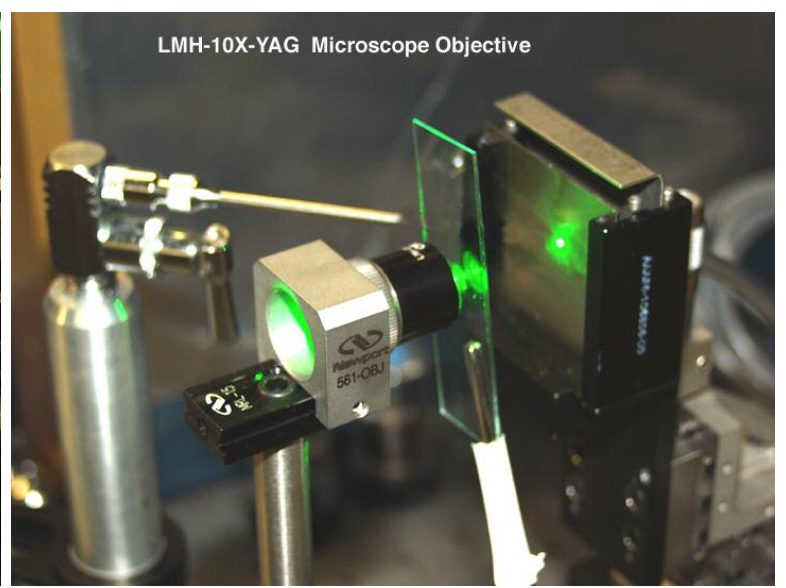

Fig. 2

The first holes were drilled were with $0.9 \mathrm{~mm}$ and1.1mm thick 304 Stainless Steel coupons. Using a $1 \mu \mathrm{m}$ resolution translation stage, 25 holes were drilled at a separation of $500 \mu \mathrm{m}$. The holes were drilled with no shield and no argon on either surface and as a result, the front surface of the hole showed a considerable amount of debris, as shown in Fig. 3. In Fig. 4, there is a piece of slag protruding form the backside of the coupon.

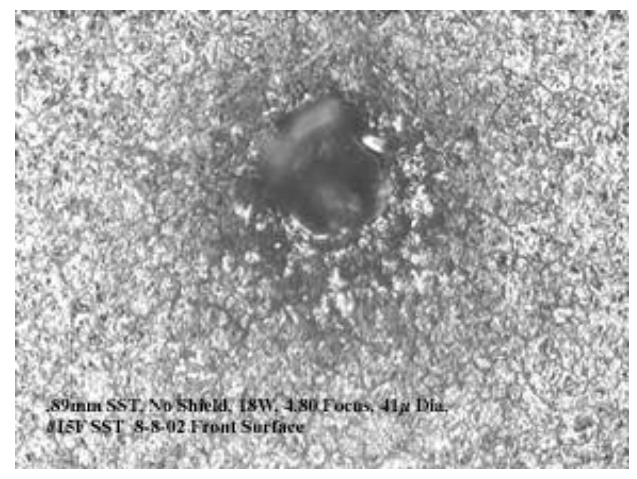

Fig. 3 .09mmSST

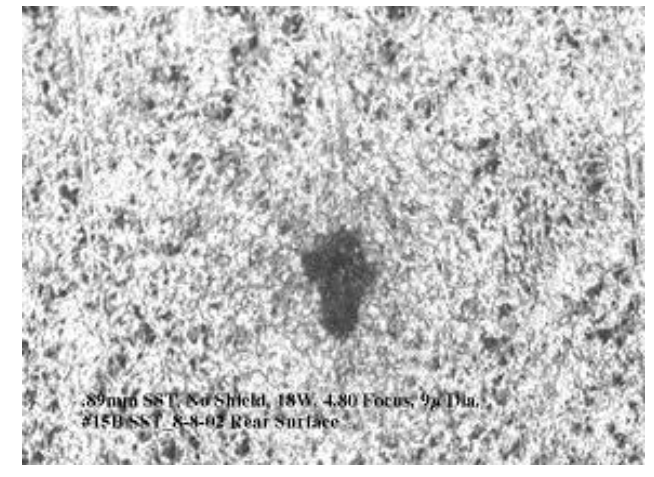

Fig. $4 \quad .09 \mathrm{mmSST}$

The second step was to use a $.05 \mathrm{~mm}$ SST shield held in front of the SST coupon. A dramatic improvement resulted, providing the shield is held very tight to the surface of the coupon. . The shield serves to clip the wings of the profiled laser beam to reduce melting of the edges and allows only the high power beam to ablatively drill the hole.

A series of 25 holes were drilled per coupon at incremental focal distances in order to optimize the efficiency of the drilling process. The distance from the microscope objective, (10 $\mathrm{mm}$ aperture with a $35 \mathrm{~mm}$ focal length) to the coupon was varied in steps of 200 microns. The optimum distance from the microscope objective to the coupon was $34 \mathrm{~mm}$. By placing the microscope objective at this optimum position, the laser drilled holes showed little taper and the diameter at the front surface as the rear surface were roughly equal, as shown in Figs. $5 \& 6$. 


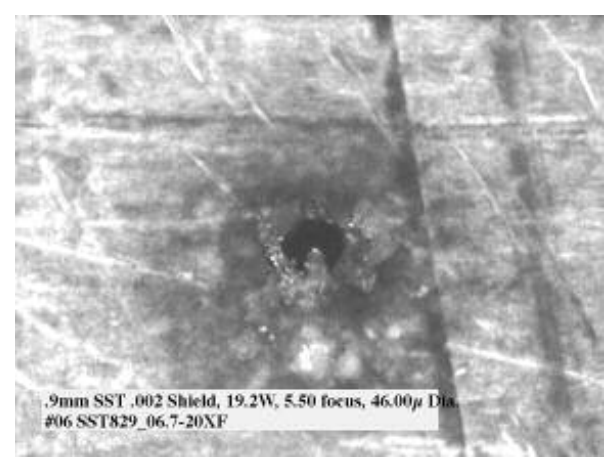

Fig. 5 0.7mm SST

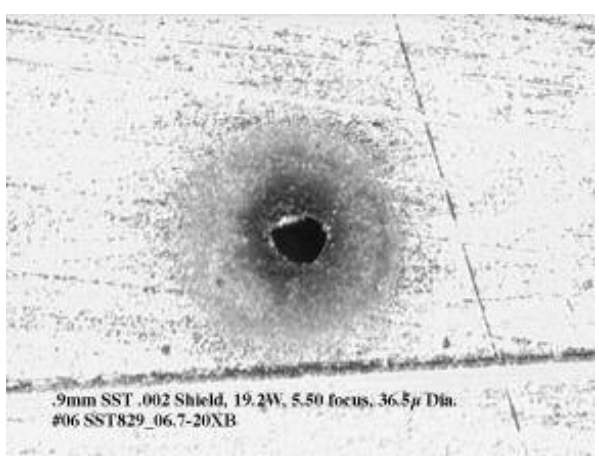

Fig.6 $\quad 0.7 \mathrm{~mm} \mathrm{SST}$

A cross sectional view of the holes was made by sectioning the coupon, followed by polishing and acid etching to reveal the grain structure. An example is shown in Fig. 7. These holes have an aspect ratio of 20-30 with little taper and show no HAZ, as evidenced by the appearance of grain boundaries up to the hole. The larger section in the center of the hole is may be caused by greater heating, which resulted in more vaporization of the center section than the entrance or exit. Upon cooling the center section was widened of the hole due to more material being removed.

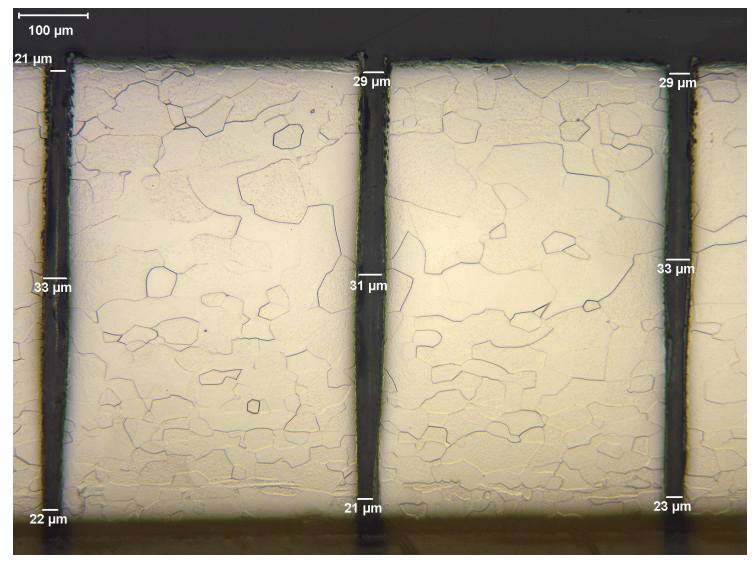

Fig. $7 \quad 0.7 \mathrm{~mm}$ Stainless Steel

Stainless Steel contains 50\% iron and when heated to elevated temperatures near the melting point, iron oxides are formed on the surfaces of the coupon. To reduce this effect, nickel was chosen as a good candidate for precision holes since it resists corrosion and oxidation. Using the same drilling parameters as with stainless steel and with a $.05 \mathrm{~mm}$ shield in front but no argon gas flow on the rear surface, several nickel coupons were drilled. The quality of 
the laser-drilled holes was excellent. There was a very tiny amount of taper at the beginning of the hole with no slag or melted material at the hole entrance or exit, (See Fig. 8 \& 9).

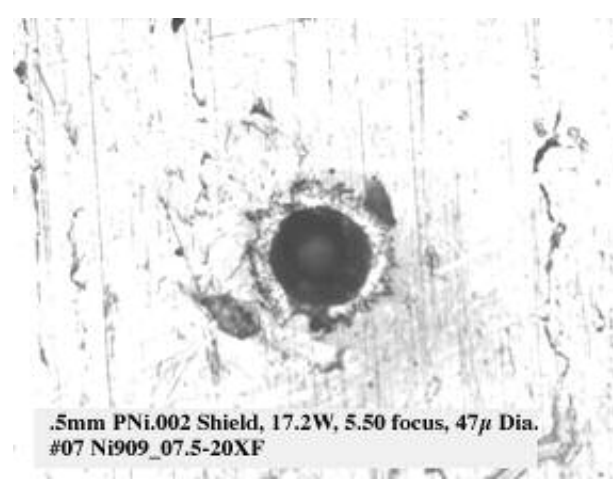

Fig. 8 0.5mm Nickel

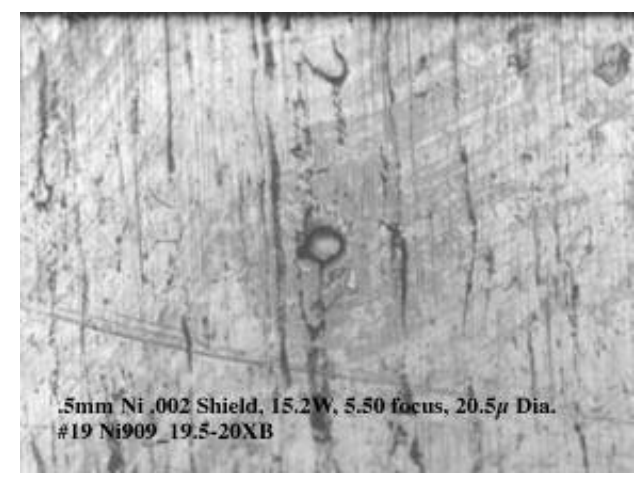

Fig. 9 0.5mm Nickel

Cross section of the $0.5 \mathrm{~mm}$ Nickel coupon is shown in Fig. 10.

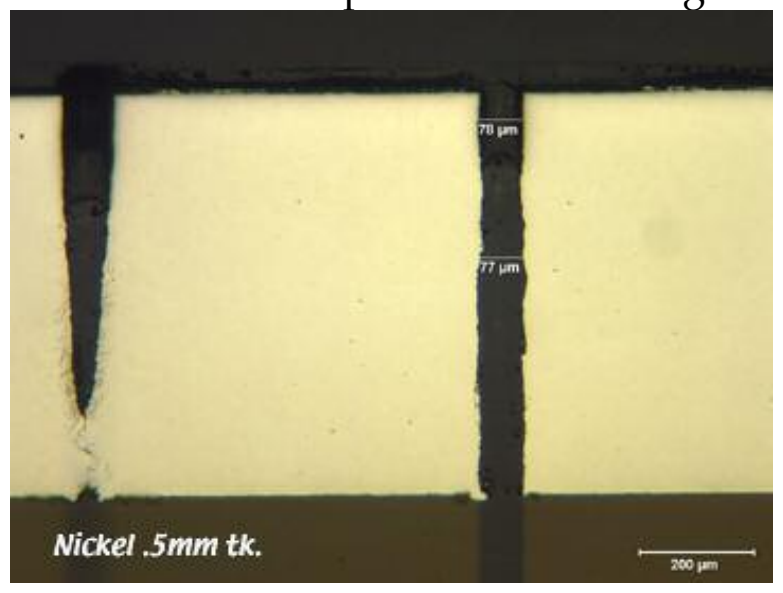

Fig. 10 0.5mm Nickel

There was interest from the NIF diagnostic community in drilling $25 \mu \mathrm{m}$ diameter holes in tantalum substrates of thickness close to a millimeter. Due to the refractive nature of tantalum, ablative hole drilling is more difficult than for non refractive metals. The 16 watt pulsed beam could not penetrate a thickness of $0.9 \mathrm{~mm}$. Experiments on thinner substrates showed that 3 seconds were required to penetrate $0.5 \mathrm{~mm}$ of tantalum and 10 seconds for $0.7 \mathrm{~mm}$. A .05mm SST shield was used with the sheet held in tight contact with the front surface. No argon flow was used during the hole drilling. The drilled hole microphotograph results for the $0.5 \mathrm{~mm}$ Tantalum is shown in Fig. 11 and the results for the $0.7 \mathrm{~mm}$ Tantalum is shown in Fig. 12. 


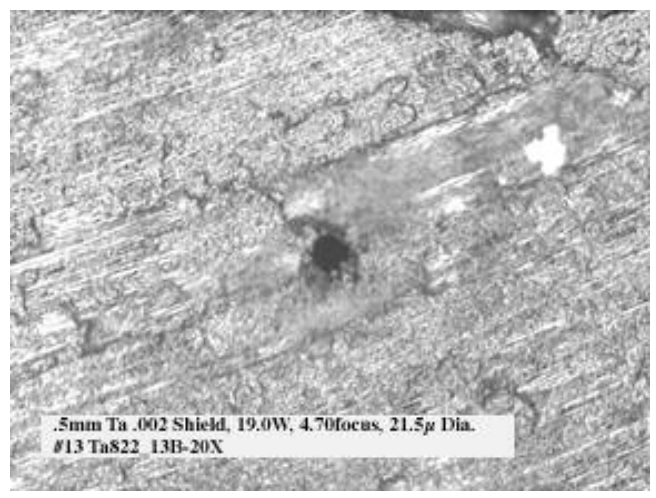

Fig. $11 \quad 0.5 \mathrm{~mm}$ Tantalum

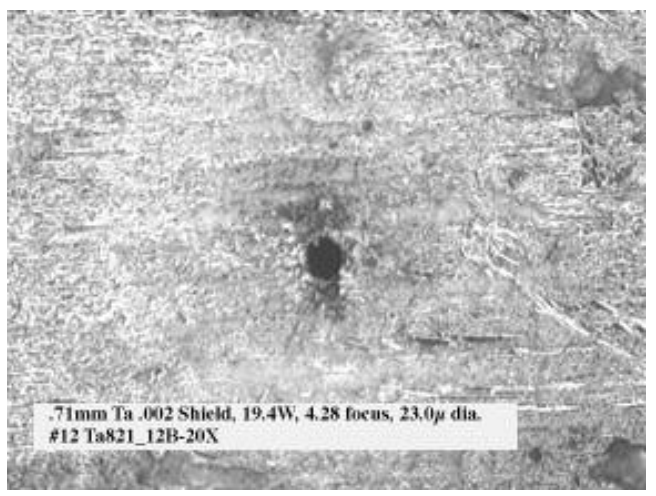

Fig. $12 \quad 0.7 \mathrm{~mm}$ Tantalum

The Tantalum coupon Fig. 12 was then cross-sectined and is shown in Fig. 13.

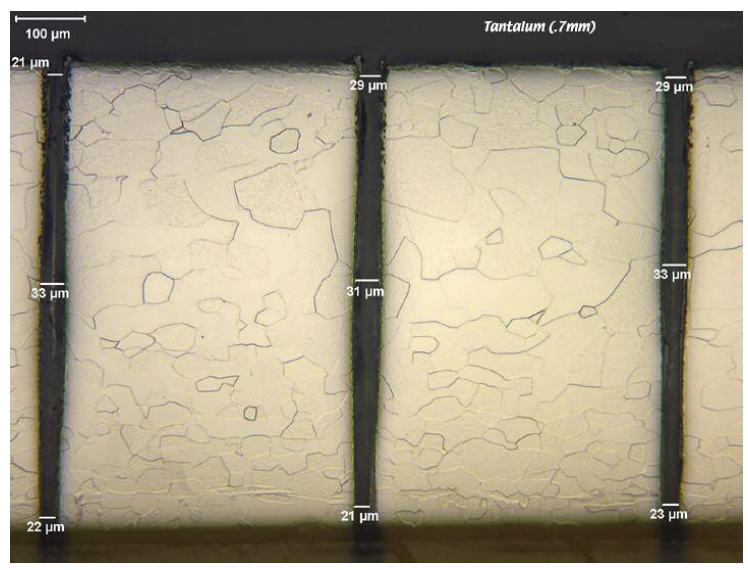

Fig. 13 0.7mm Tantalum

There were other metals of interest for this precision hole drilling technique. For another NIF diagnostic, a two dimensional array of holes 25 microns in diameter were to be drilled in a $0.5 \mathrm{~mm}$ platinum substrate with spacing of 200 microns. Again, we used a $.05 \mathrm{~mm}$ shield in front of the platinum coupon. The best holes were obtained when the mask remained in intimate contact with the platinum as usual. This procedure was difficult to perform with the present setup. The reason being is that in order to secure the flexible foil sheet in intimate contact, it would require a more elaborate clamping arrangement then was provide for these laser experiments. Both front and rear surfaces were blackened around the holes as indicated in Figs. $14 \& 15$ and a post drilling cleaning technique is required to remove the blackened surface. 


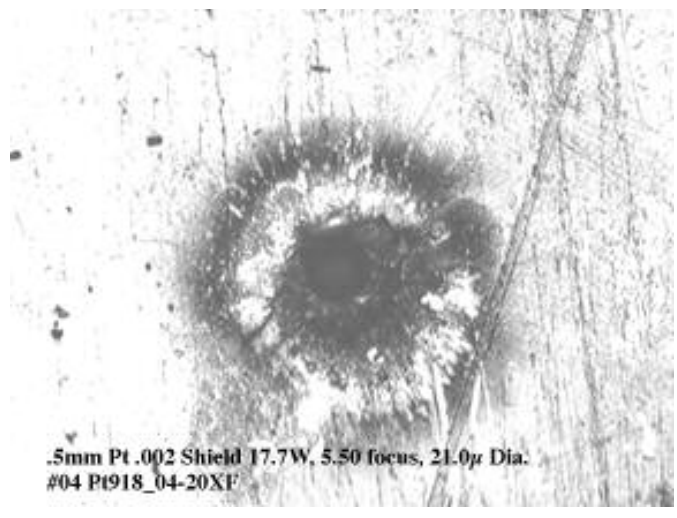

Fig. 14 0.5mm Platinum

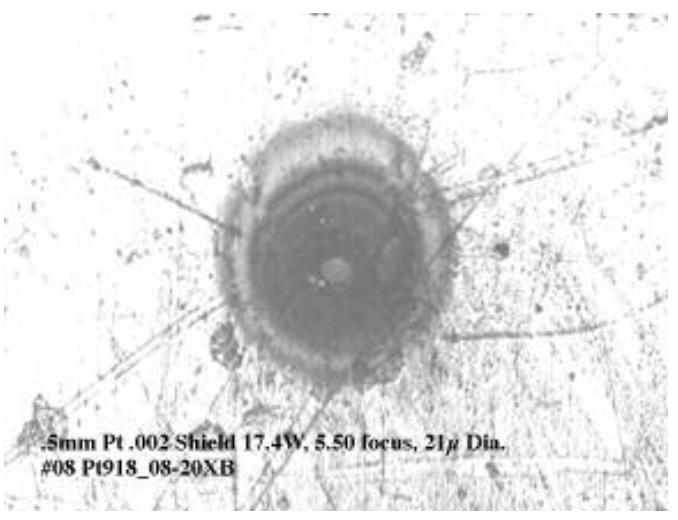

Fig. 15 0.5mmPlatinum

Laser drilled holes were also done in $0.8 \mathrm{~mm}$ thick platinum. The technique was the same as the $0.5 \mathrm{~mm}$ thick platinum and the drilling time was about the same as stainless steel. There was a large amount of blackening on the front surface, as can be seen in Fig. 16 while the back surface blackening was minimal as can be seen in Fig. 17.

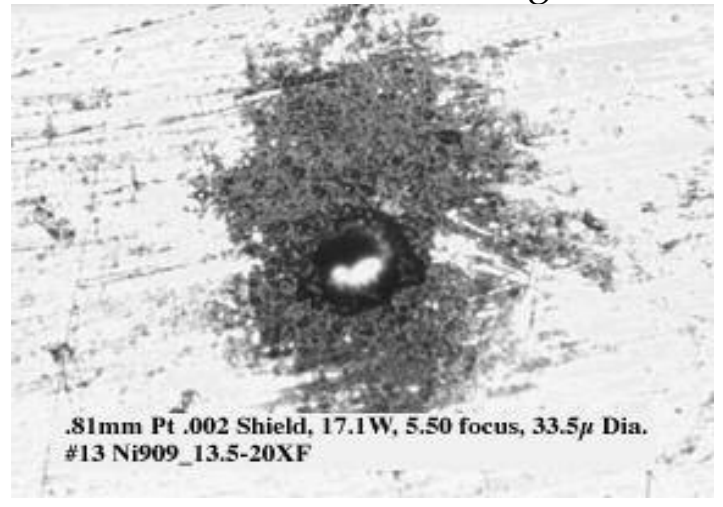

Fig. 16 0.81mm Platinum

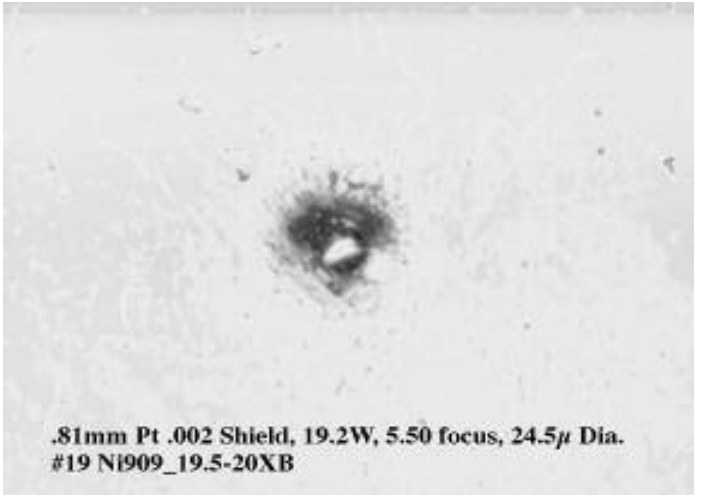

Fig. 17 0.81 Platinum

Coupons of the $0.5 \mathrm{~mm}$ and $0.8 \mathrm{~mm}$ thick platinum were cross-sectioned to expose the laser-drilled holes as shown in Fig. 18 and 19. Cross-Sectioned hole measurements were $23 \mu \mathrm{m}$ to $28 \mu \mathrm{m}$ in diameter for the $0.5 \mathrm{~mm}$ platinum, resulting in a very uniform hole throughout its length. Hole dimensions measured $19 \mu \mathrm{m}$ to $25 \mu \mathrm{m}$ for the $.8 \mathrm{~mm}$ platinum. These laser drilled holes showed very little evidence of taper. 


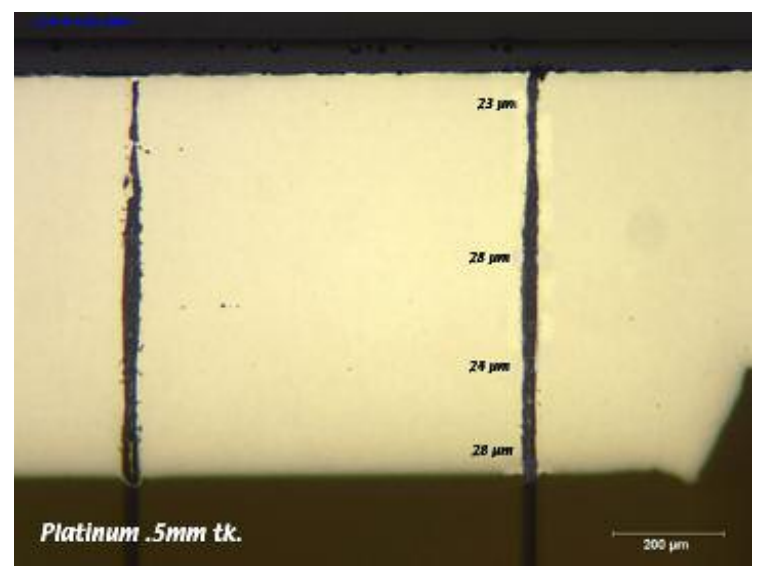

Fig. 18 0.5mm Platinum

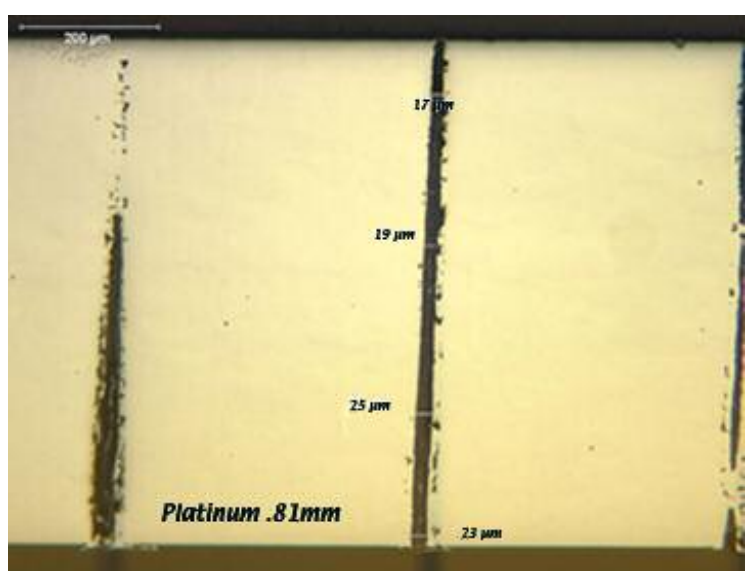

Fig. 19 0.81 Platinum

As a comparison, platinum coupons were sent to Resonetics in Nashua, NH, a commercial laser machining shop. The results are shown in Figs. 20 \& 21. It appears that Resonetics uses some method to remove the blackening and the next set of experiments will concentrate on methods of protecting the surface or post drilling surface cleaning

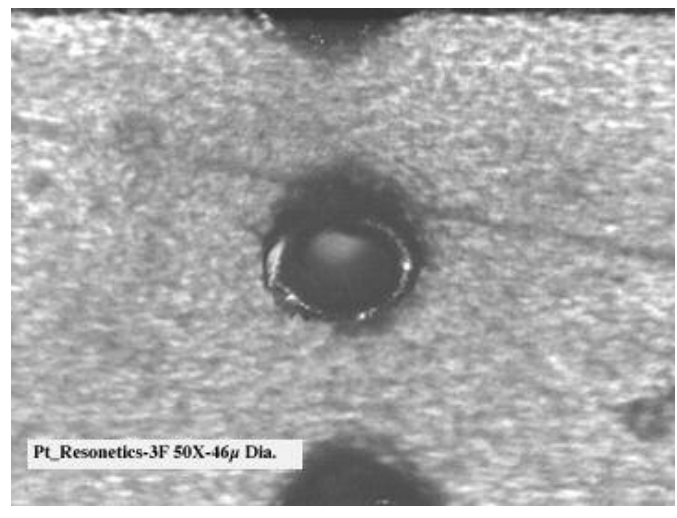

Fig. 20 Resonetics $0.5 \mathrm{~mm} \mathrm{Pt}$

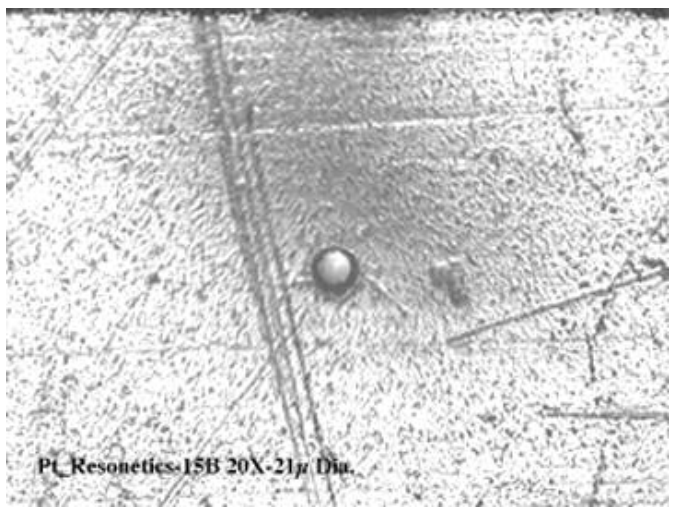

Fig. 21 Resonetics $0.5 \mathrm{~mm} \mathrm{Pt}$

For a detailed comparison of the LLNL and Resonetics drilled holes, the coupon from Resonetics was cross sectioning and is shown in Fig. 22.

Dimensions measured for these holes showed a large degree of taper with the diameter varying from $39 \mu \mathrm{m}$ in the middle of the coupon to $69 \mu \mathrm{m}$ in diameter at the entrance of the beam. These holes are much larger and have more taper than was requested. By way of explanation, the Eximer laser used by Resonetics has a much poorer beam quality with many higher order modes than does the frequency doubled DPSSL laser. However, the drilling technique may have used a mask-imaging system in which case the beam quality per se may not be the 
relevant parameter. We need to know more about the Resonetics technique in order to explain their results.

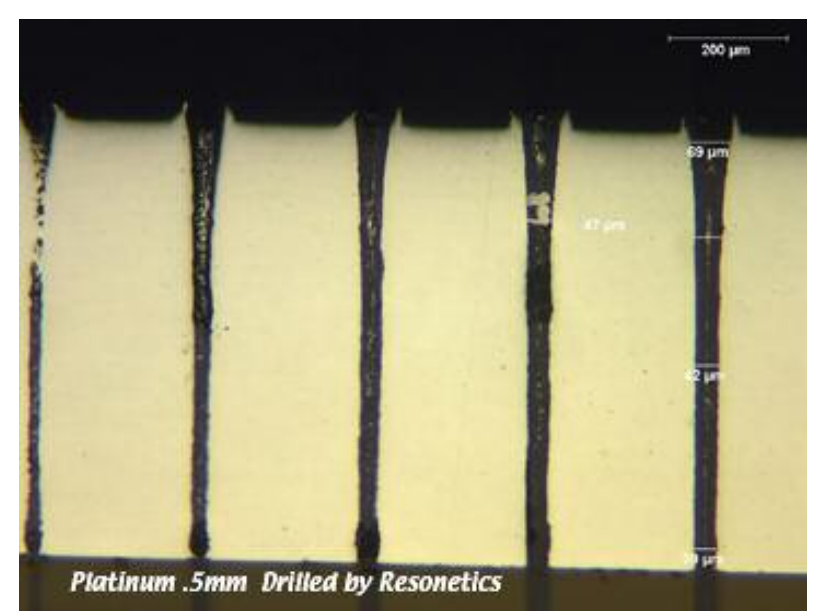

Fig. 22 Resonetics, $0.5 \mathrm{~mm} \mathrm{Pt}$

\section{Trepanning of Laser Drilled Holed}

Trepanning is a milling technique wherein a small diameter cutting tool is run around the edge of a hole in order to bring the dimensions of that hole to precision dimensions. In the case of laser drilling of circular holes, inserting two wedges in the optical beam path and having them rotate with respect to each other produces a rotating offset of the laser beam with respect to the optical axis.

The trepanning fixture, used in this application, is shown in Fig. 23 with the frequency double laser beam. It consists of a pair of one-degree wedges, which can be translated with respect to each other to adjust the amount of offset of the laser beam. One-degree wedges were chosen to provide a maximum offset of about $300 \mu \mathrm{m}$. A small motor, which is not visible in Fig.23, rotates the wedge pair to produce a circular pattern. Calibrations were made of the trepan fixture in order to quickly dial in the desired offset for drilling different size holes. This was determined by drilling 4 holes at $90^{\circ}$ and measuring the separation of the holes, see Fig.24. Three sets of holes were drilled which correspond to the wedge position for the two extreme positions and in the center position. This procedure was performed to determine the, "Zero" position and the furthest deflection of the laser beam. Then by applying a scale to one of the wedge flanges, and a reference mark to the main body of the trepanning fixture, the flange could be 
calibrated in degrees versus beam offset. This calibration was calculated to be $3^{\circ} /$ tic mark which provides an offset of $5.33 \mu \mathrm{m} /$ tic mark.

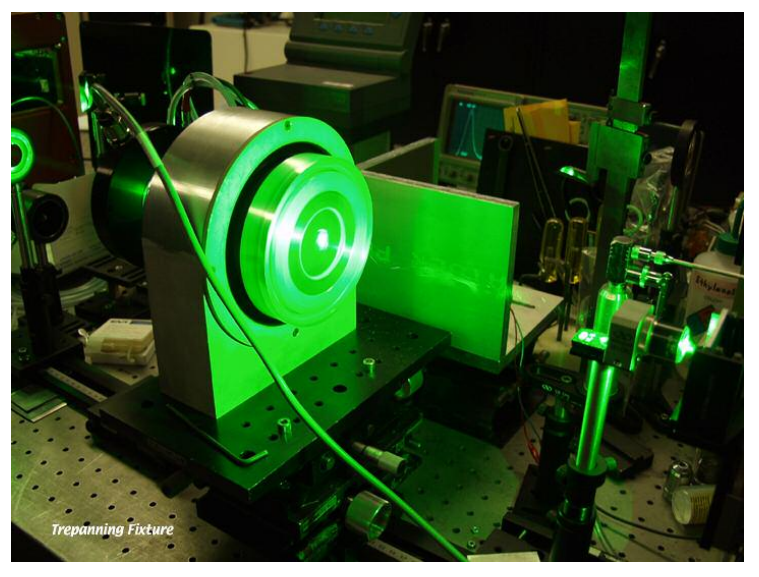

Fig. 23

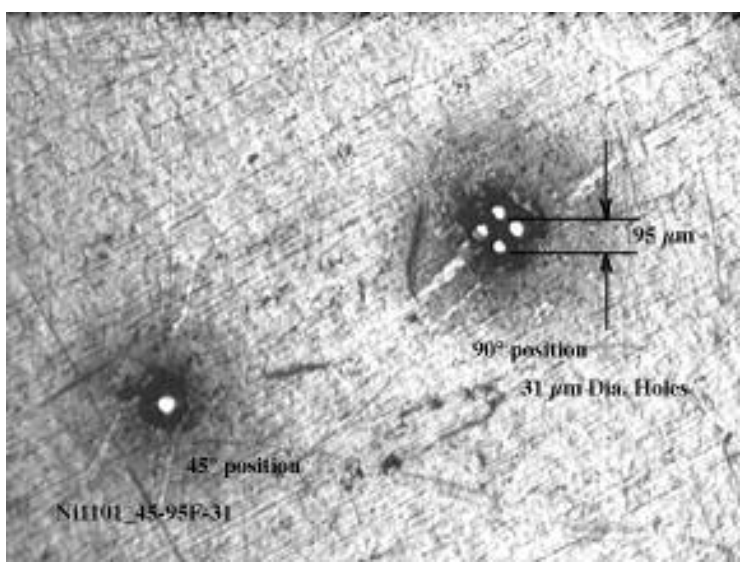

Fig. 24

A rough hole, is shown on the right side of Fig. 25, was first drilled in $0.5 \mathrm{~mm}$ nickel by rotating the fixture for 2 minutes with $16 \mathrm{~W}$ of $532 \mathrm{~nm}$ laser power. (In a practical application, a 300W IR Laser would drill the rough hole in a fraction of the drill time required here.) The trepan fixture was then adjusted to give an additional offset of 15 microns and the rough hole was "trepanned" with an additional cutting time of 15 seconds, see Fig. 25 left side. A second coupon, Fig. 26 was also rough drilled at 2 minutes, but with the trepanning reduced to 5 seconds. Note the resulting smaller finished hole diameter of Fig. 26.

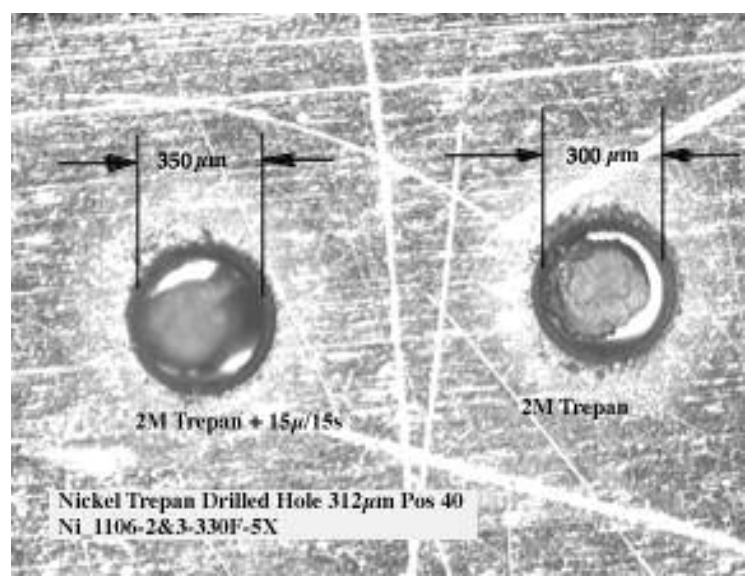

Fig. 25

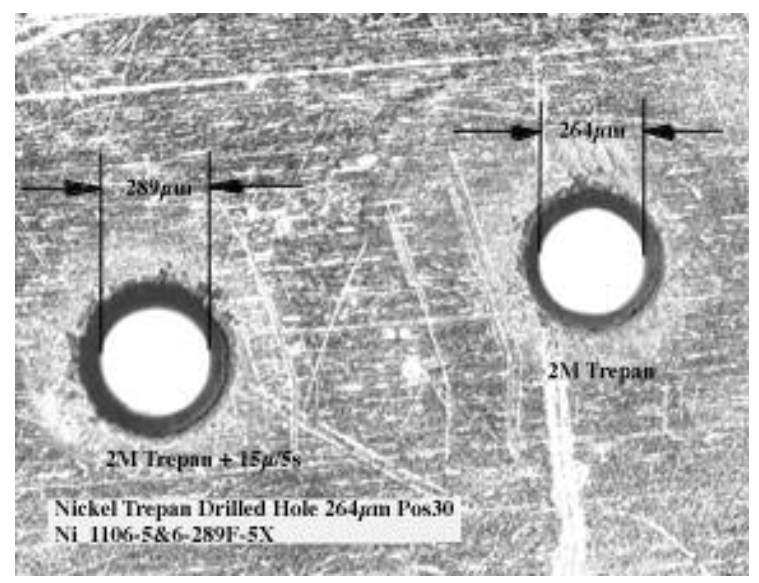

Fig. 26

The time required for the trepanning must be short to accommodate the high through put needed in applications involving large numbers of holes. In order to quantify the time needed for the trepan step, a series of drilled holes were made by varying the trepanning time between 1 and 5 seconds. A 5 second dwell time appeared to give the best finish for the $340 \mu \mathrm{m}$-drilled hole in Fig. 27. 
Figure 28 shows the backside to the nickel coupon of the same trepanned drilled hole.

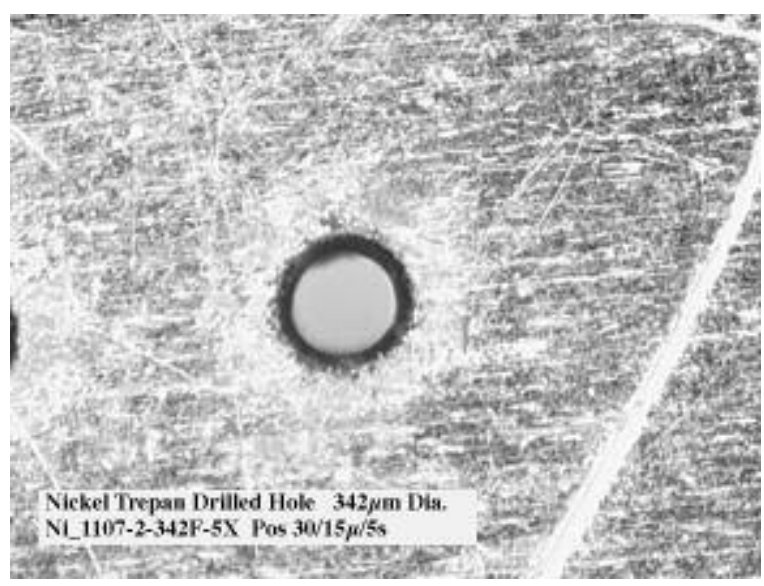

Fig.27

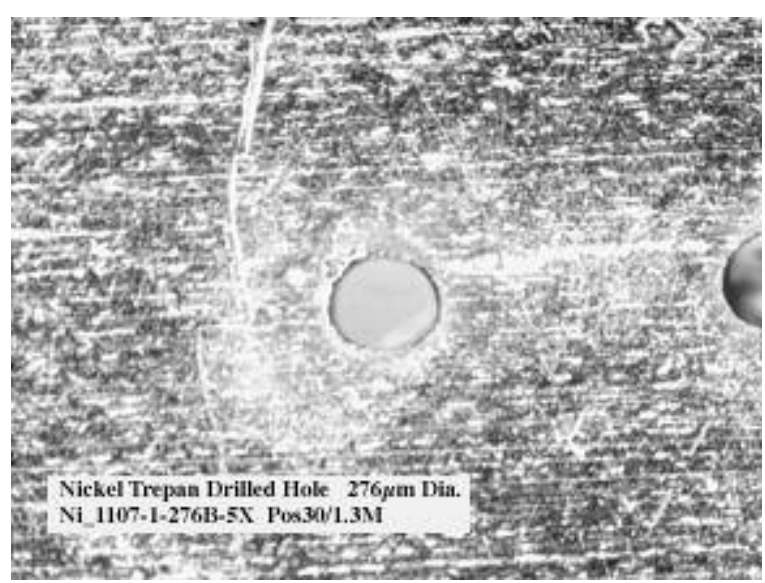

Fig. 28

All the trepanned drilled holes thus far have been drilled with the green laser power at 16 Watts, $75 \mathrm{~ns} @ 13 \mathrm{Khz}$. For a $300 \mu \mathrm{m}$ diameter hole the Trepanning fixture was set at 40 tic marks, which is equal to 120 degrees. With a calibration of $1.78 \mu \mathrm{m} /$ degree, the calculated diameter would be $213 \mu \mathrm{m}$ diameter. However, since the laser beam at the focal point is Gaussian, the actual diameter comes out to be approximately $100 \mu \mathrm{m}$ larger in diameter, or $310 \mu \mathrm{m}$. Then with a finishing cut of $15 \mu \mathrm{m}$ offset, the final hole is about $340 \mu \mathrm{m}$ diameter. The microscope objective focus lens used on these trepanning experiments is an LMH-10X-YAG (OFR, Caldwell, N.J.), with an effective working distance of $15 \mathrm{~mm}$.

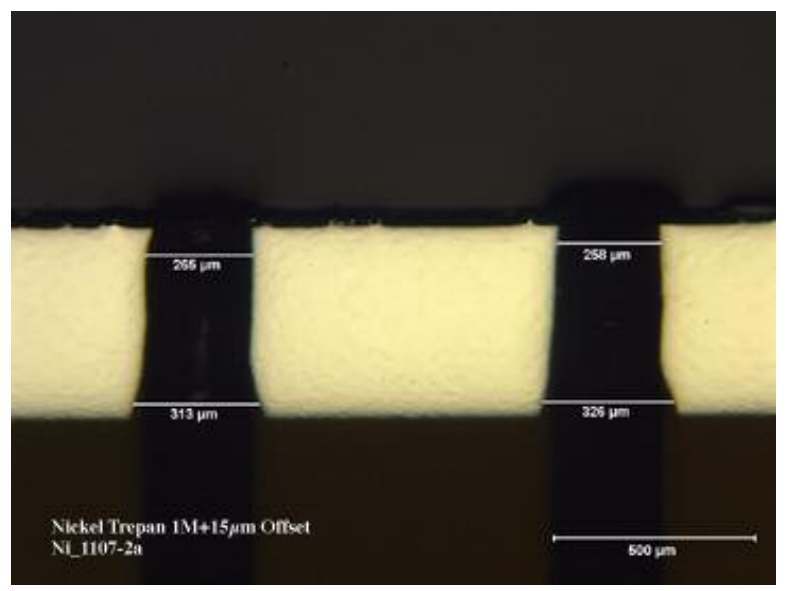

Fig. 29

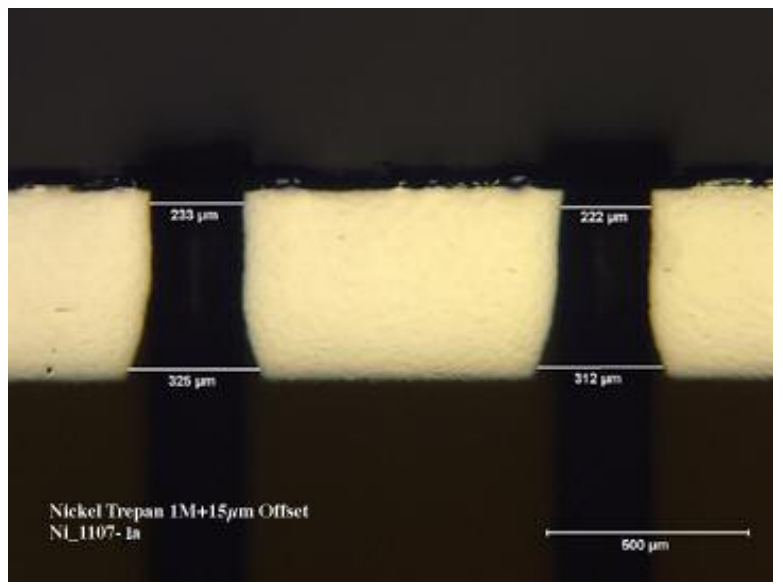

Fig. 30

In order to quantify the effect of trepanning on the profile of the hole, a cross section of the trepanned holes was prepared as shown in Figures 29 
$\& 30$. From the cross-sectioned measurements, the optimum laser dwell time for minimum taper was still unclear. A second series of holes were drilled at with an offset of $15 \mu \mathrm{m}$ and the dwell time increased to 10 seconds. Also, a series of holes were made with an offset of $30 \mu \mathrm{m}$ with the same dwell time. A 5 second dwell time resulted in a hole diameter of $276 \mu \mathrm{m}$ on the front surface backside and $285 \mu \mathrm{m}$ on the rear side. The holes are shown in Fig. 31 and Fig. 32.

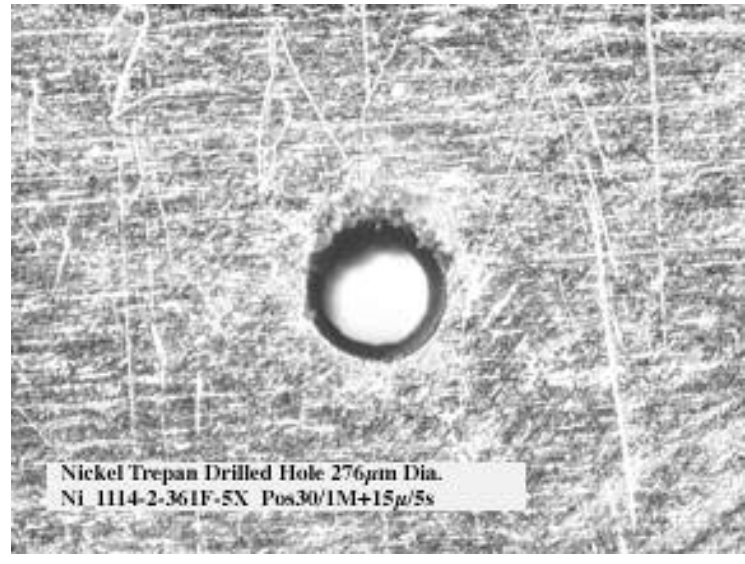

Fig. 31

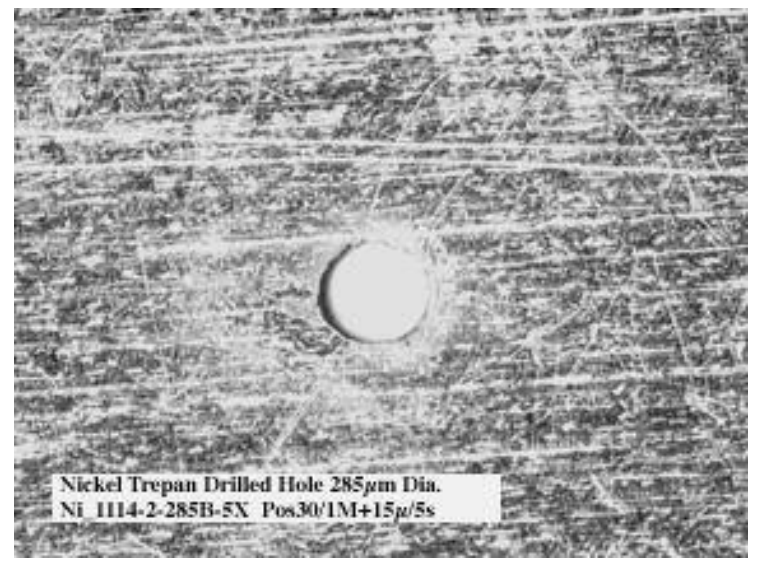

Fig. 32

Laser hole measurements taken of the 10-second time duration measured $410 \mu \mathrm{m}$ for the front surface, while the backside measured $285 \mu \mathrm{m}$. The exit hole remained the same diameter as a 5 second dwell time while the front entrance hole increased in size with the longer dwell time. These results are shown in Figs. 33 and Fig. 34.

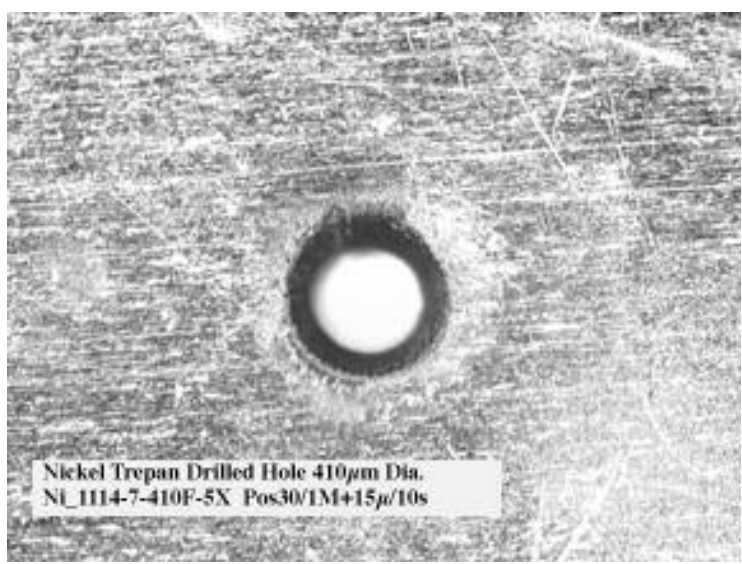

Fig. 33

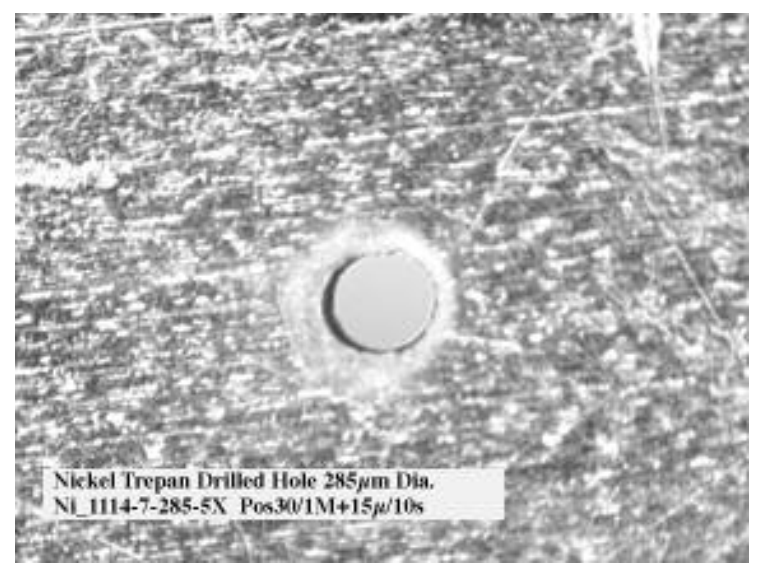

Fig.34

Cross-sectioned measurements of the same holes, (with a $15 \mu \mathrm{m}$ offset of both the 5-second and 10-second dwell time), confirmed the above 
measurements, see Fig. 35 and36. It is concluded that 5 seconds was the optimum dwell time for a straight through hole with minimal taper.

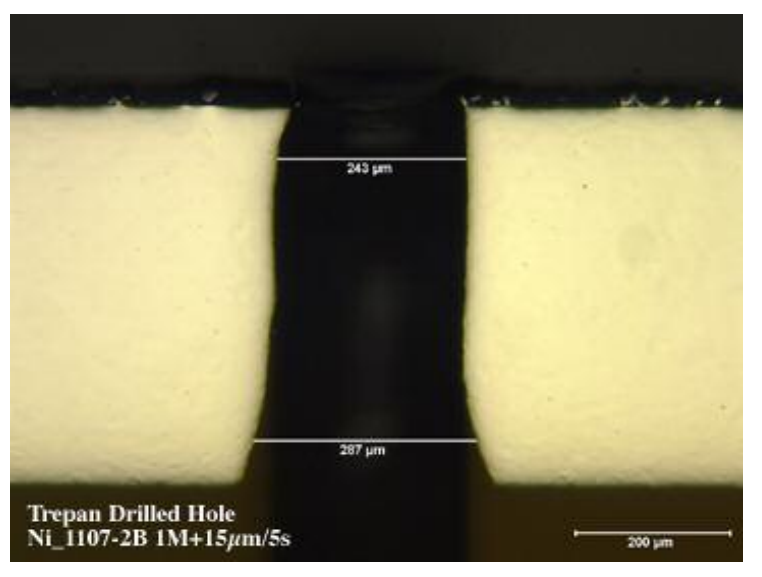

Fig. 35

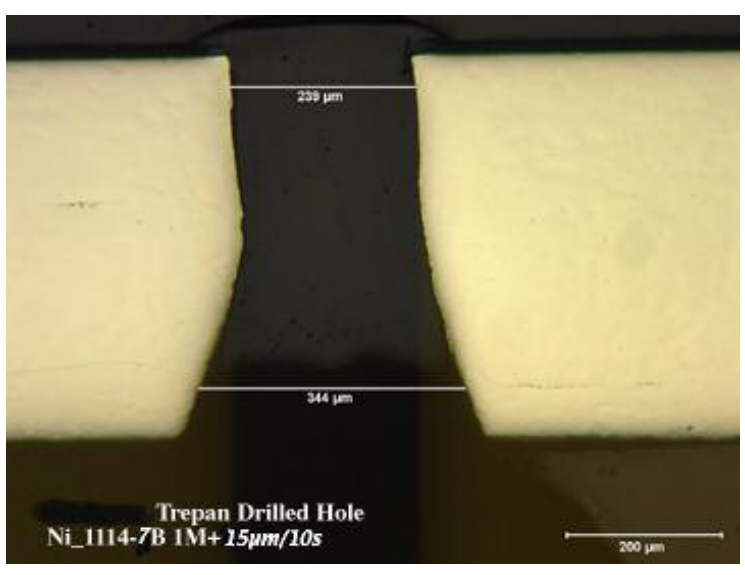

Fig. 36

Microscopic and cross-sectional measurement of these holes was very similar with a $30 \mu \mathrm{m}$ trepan offset. The hole diameter for the 5 second dwell was $347 \mu \mathrm{m}$, while the backside diameter was $276 \mu \mathrm{m}$. Then for the 10 -second dwell time, the hole diameter was $382 \mu \mathrm{m}$, while the backside was $289 \mu \mathrm{m}$. Although the offset was twice as much as the first case, the backside hole diameter did not increase proportional to the front diameter as expected. See Fig. 37 - 40.

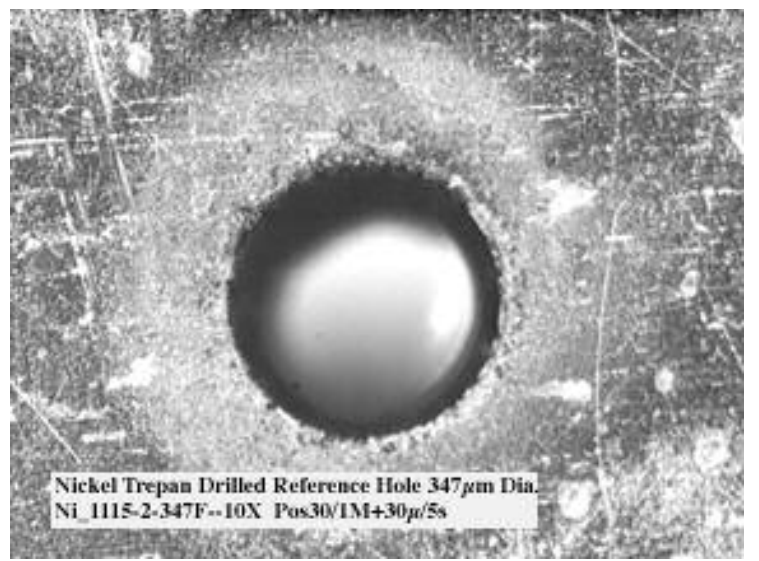

Fig. 37

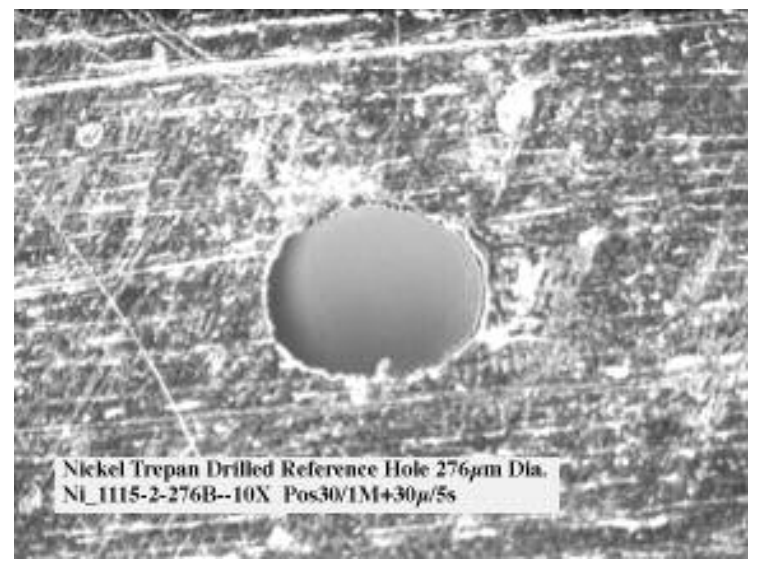

Fig. 38 


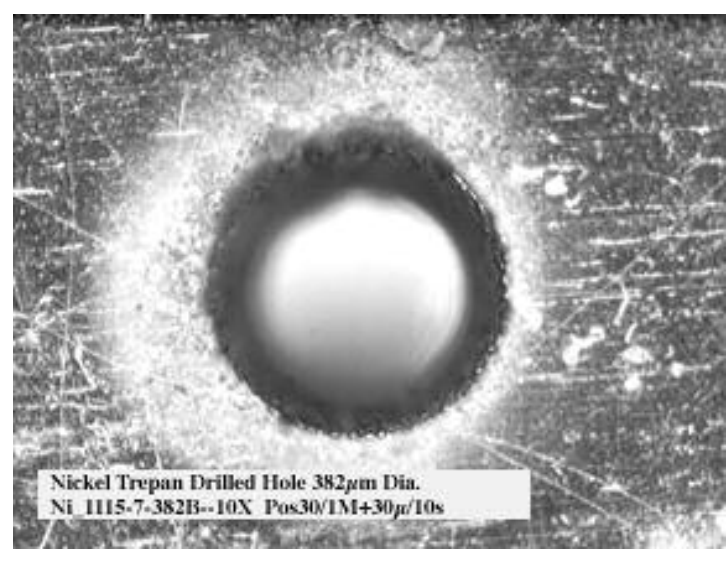

Fig. 39

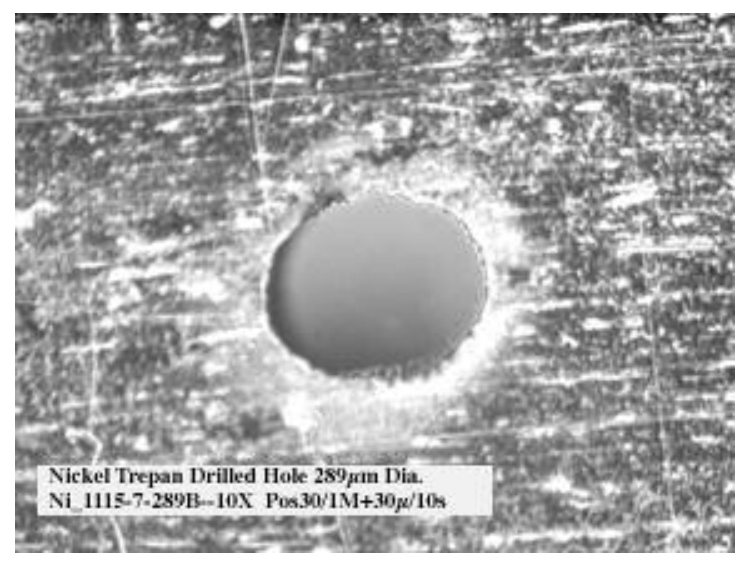

Fig. 40

\section{Summary and conclusion}

Precision laser hole drilling of $25 \mu \mathrm{m}$ diameter holes or smaller using a $3 \mathrm{X}$ diffraction limited diode pumped laser operating at about 16Watts at 532nm and a pulse length of $75 \mathrm{~ns}$ at $13 \mathrm{Khz}$ was successfully demonstrated. These precision holes have been drilled in various metals such as stainless steel, tantalum, platinum and nickel. Laser drilled holes in platinum coupons using the frequency doubled DPSSL laser are smaller and show less taper than holes drilled using the Eximer laser at Resonetics Inc. However, in order to drill an array of holes spaced at 200 micron intervals with one micron precision, we would require an interferometer controlled translation stage.

Precision laser drilled holes using the trepanning method for larger $350 \mu \mathrm{m}$ diameter holes was also successful. Smooth and round holes were drilled in nickel by using the trepan technique. After a rough hole was drilled, an offset of 15 microns with dwell time of 5 seconds was sufficient to finish the holes with little taper in nickel substrates of $0.5 \mathrm{~mm}$ thickness. Based upon the laser dwell times, it is estimated that about 1.5 hours are needed to drill a thousand holes.

\section{ACKNOWLEDGMENTS}

I would like to acknowledge the following people who have contributed input to these laser hole-drilling experiments.

\section{- Mike Shirk}

- Bob Vallier

- Mike Moran

- Brian Comaskey 
- Karl Scheibner

- Brent Stuart

- Paul Armstrong

- Richard Shuttlesworth

- Carl Westrich

- Curt Cochran 